\title{
Os mapas de sertanistas das pedras brilhantes
}

Entre o traço rústico dos sertanistas e o desenho exato da cartografia europeia

Los mapas de las piedras brillantes: entre el trazo rústico de los "sertanistas" y el diseño exacto de la cartografía europea

The sertanistas maps of diamonds: between the rustic trait of sertanistas and the exact design of European cartography

Les cartes des diamants : entre trace rustique d'explorateurs et de la conception exacte de la cartographie européenne

\section{Carmem Marques Rodrigues}

\section{Q OpenEdition}

\section{Journals}

\section{Edição electrónica}

URL: https://journals.openedition.org/terrabrasilis/2366

DOI: 10.4000/terrabrasilis.2366

ISSN: 2316-7793

Editora

Rede Brasileira de História da Geografia e Geografia Histórica

Refêrencia eletrónica

Carmem Marques Rodrigues, "Os mapas de sertanistas das pedras brilhantes», Terra Brasilis [Online], 9 | 2017, posto online no dia 29 dezembro 2017, consultado o 05 dezembro 2022. URL: http:// journals.openedition.org/terrabrasilis/2366 ; DOI: https://doi.org/10.4000/terrabrasilis.2366

Este documento foi criado de forma automática no dia 5 dezembro 2022

All rights reserved 


\section{Os mapas de sertanistas das pedras brilhantes}

Entre o traço rústico dos sertanistas e o desenho exato da cartografia europeia

Los mapas de las piedras brillantes: entre el trazo rústico de los "sertanistas" y el diseño exacto de la cartografía europea

The sertanistas maps of diamonds: between the rustic trait of sertanistas and the exact design of European cartography

Les cartes des diamants : entre trace rustique d'explorateurs et de la conception exacte de la cartographie européenne

Carmem Marques Rodrigues

\section{Dos mapas sertanistas à Nova História da Cartografia}

1 Era 4 de julho de 1730 quando o padre Diogo Soares escreveu a primeira carta ao Rei D. João $\mathrm{V}$ relatando as novidades e os progressos de seu trabalho no Brasil. Junto com o padre italiano Domingos Capassi, estavam no Rio de Janeiro há apenas cinco meses, ainda se adaptando aos ares do Novo Mundo, porém a tarefa que carregavam não permitia descanso. Tinham sido enviados pelo Rei para mapear o mais exatamente possível o Brasil, a fim de municiar Portugal com mapas precisos de sua colônia. $\mathrm{Na}$ carta, Soares descreve as medições que já tinha realizado e o seu trabalho de coletar informações, incluindo "vários roteiros e mapas dos melhores sertanistas de São Paulo e Cuiabá, Rio Grande e da Prata" (AHU, Carta de 4 de julho de 1730).

2 Foi essa citação da carta de Soares que instigou a curiosidade de Jaime Cortesão sobre a existência de mapas ainda desconhecidos do interior do Brasil, por isso debruçou-se sobre o acervo cartográfico da Biblioteca Nacional e lá encontrou diversos mapas "traçados a pena e a lápis sobre folhas de papel de grosseiro fabrico" (Cortesão, 2009: 231), que pelo estilo rudimentar e pelas áreas representadas classificou como mapas 
sertanistas. Grande estudioso da cartografia do Brasil, a classificação de Cortesão tornou-se clássica.

3 Atualmente os manuscritos estão disponíveis digitalmente no site da Biblioteca Nacional, são relativamente conhecidos e referenciados por diversos autores, porém poucos foram os pesquisadores que estudaram esses mapas à luz da História da Cartografia, mais especificamente pelo viés da Nova História da Cartografia. Seus principais expoentes, John Harley, David Woodward, Christian Jacob, Mattew Edney, John Fels e Dennis Wood, trouxeram uma nova orientação metodológica para a interpretação dos mapas, que em intercâmbio com conceitos filosóficos, literários, sociológicos e científicos, abriu caminho para o processo de entendimento dos mapas para muito além da sua correspondência com o território.

4 Em sua tese de doutorado, Thiago Kramer de Oliveira (2012) analisou alguns mapas sertanistas da região de Cuiabá sob a ótica da Nova História da Cartografia, problematizando, inclusive, a clássica definição de mapas sertanistas. Em diálogo com esse estudo, analisamos em nossa dissertação de mestrado cinco mapas sertanistas e quatro mapas de engenheiros da região do Serro do Frio em Minas Gerais (Rodrigues, 2014). Propomos nessa comunicação focar a discussão em dois mapas sertanistas que acreditamos que são exemplos significativos de como podemos aplicar a Nova História da Cartografia e dialogar com a leitura clássica de Cortesão.

5 No ensaio Textos e contextos da interpretação dos primeiros mapas, John Harley (2005: 60) aponta que o pressuposto comum "sobre a natureza dos mapas é que eles são uma imagem do real, uma representação gráfica de algum aspecto do mundo real". Portanto, a principal tarefa dos mapas seria manifestar concretamente uma realidade geográfica, mesmo que a habilidade do cartógrafo seja um fator relevante, nossa cultura ilustrada definiu que o aspecto científico é o principal. Esse conceito, amplamente aceito, interfere nas estratégias interpretativas dos historiadores que acabam compelidos a ler os mapas como imagens verdadeiras ou falsas do real. Porém, a proposta de Harley (2005: 61) é que os mapas na verdade "reescrevem o mundo, igual a qualquer outro documento, em termos de relações e práticas de poder, preferências e prioridades culturais". Por isso os "mapas sempre mostram mais que a soma inalterada do conjunto de técnicas" (Harley, 2005: 61).

6 Nesse sentido que Mattew Edney (2007: 49) propõe que os historiadores da cartografia devem fazer suas "narrativas históricas e cartobibliográficas não sobre as regiões e os lugares mapeados, mas no contexto em que os mapas foram produzidos e utilizados". 0 desvelamento dos contextos promove uma radical mudança de postura dos mapas na história, pois além "reflexos da sociedade e da cultura que os produziu, podem ser vistos claramente como contribuintes à constituição dessas sociedades e dessas culturas" (Edney, 2007: 50).

7 Como afirma Júnia Furtado (2013a: 23), uma das principais expoentes da História da Cartografia no Brasil, "podemos compreender os mapas produzidos no passado, como fazemos da mesma forma com outros documentos outrora produzidos, a partir do conhecimento dos elementos que compunham a cultura na qual eles foram formulados". É justamente essa postura metodológica que marca a Nova História da Cartografia, pois ela pretende ir muito além da "utilização de um mapa enquanto ilustração do argumento esboçado", na verdade pretende se valer "da cartografia enquanto fonte histórica" (Furtado, 2013a: 23). 
Quando Jaime Cortesão se deparou com os inúmeros mapas rústicos da Biblioteca Nacional foi com grande emoção que se lembrou da citação de Soares, afinal, como estudioso da formação territorial brasileira e da cartografia, se viu diante de um tesouro capaz de responder tanto sobre os territórios representados como sobre quem poderiam ser seus autores. $\mathrm{O}$ conjunto cobria quase todo o território brasileiro, sendo mais numerosos os que representavam São Paulo e suas adjacências, seguido das "cartas monográficas das Minas e, em particular, do Serro do Frio" (Cortesão, 2009: 232). Para Cortesão esses eram definitivamente os mapas sertanistas aos quais Soares se referiu na carta, porém somente uma análise detida de tais documentos poderia trazer luz a um problema que o incomodava, a quais sertanistas cartógrafos Soares se referia?

Um dos temas preferidos de Cortesão eram as Bandeiras, por isso tinha uma visão bastante ampla sobre a categoria de sertanista.

Dentro desta classificação cabem, é certo, bandeirantes propriamente ditos, isto é, sertanistas de São Paulo, moldados pelo gênero e o estilo de vida do bandeirismo, e simples sertanistas de ocasião, - luso-brasileiros doutras capitanias, reinóis de há muito residentes no Brasil, ou até servidores oficiais, civis ou militares, a quem o discorrer, em funções do Estado, por extensos territórios prestasse uma consciência aguda do espaço e a possibilidade de o representar. (Cortesão, 2009: 232)

Ao se debruçar sobre os mapas sertanistas alguns deles lhe chamaram a atenção para dois aspectos: a rudeza dos traços e a capacidade de síntese do desenho. Tendo em mente os bandeirantes, Cortesão concluiu que podia separar os mapas em dois grupos, os mapas sertanistas e os mapas de bandeirantes, este último representava uma arte cartográfica nativa que tinha como principal característica o primitivismo do indígena. Principalmente os mapas que representavam o espaço das moções eram marcados pelo "arcaísmo índio do traçado, vincadamente esquemático, cingindo-se quase sempre à rede hidrográfica, ou seja, aos sulcos que o tempo cavou no território e cujo conhecimento, por necessidade vital, maior atenção e interesse mereceu do aborígene". (Cortesão, 2009: 232) Por outro lado, os mapas sertanistas, que Cortesão (2009: 232) também chamou de "cartografia sábia, apresentam uma arte e cultura plástica, muito mais evoluídas".

11 Diante das conclusões de Cortesão nos perguntamos: entre os mapas sertanistas do Serro do Frio podemos encontrar aqueles que têm traços indígenas? Quais características levaram Cortesão a afirmar que os mapas sertanistas também correspondiam a uma cartografia sábia? Analisando dois mapas sertanistas, Mapa de parte de Minas Gerais e Carta topográfica da vila do Príncipe no Serro Frio e do seu distrito, que propomos tentar responder a estas perguntas à luz da Nova História da Cartografia.

\section{Os sertanistas da Comarca do Serro do Frio}

12 A colonização da região do Comarca do Serro do Frio se iniciou no alvorecer do século XVIII como um desdobramento do processo de expansão geográfica resultante da busca por ouro e esmeraldas, desde então, foi o local de passagem de algumas das grandes bandeiras paulistas (Lima Jr, 1945: 15). Esse território é banhado por vários rios, sendo o mais importante o Jequitinhonha com sua bacia hidrográfica. Muitos desses rios cedo se revelaram auríferos, e, por isso, vários aventureiros se estabeleceram nas suas margens, onde rapidamente floresceram alguns núcleos urbanos. 
13 Lucas de Freitas foi um dos primeiros povoadores da área e, nas proximidades das chamadas "velhas lavras de Lucas de Freitas" formou-se um pequeno arraial que se expandiu de forma rápida, transformando em 29 de janeiro 1714 na Vila do Príncipe. Pouco tempo depois, em 1720, foi criada a Comarca do Serro do Frio, uma evidência da expansão econômica e demográfica da área que tinha na mineração de ouro sua principal atividade, concomitante ao comércio do gado e à agricultura de gêneros alimentícios. Porém, nos anos finais dessa década começaram a surgir notícias sobre o aparecimento de diamantes em córregos próximos ao pequeno arraial do Tejuco, o que provocou um intenso aparecimento de aventureiros de toda a sorte. Mas como esses homens conseguiam percorrer os imensos e desconhecidos sertões das Minas Gerais? Joaquim Felício dos Santos (1976: 41), de forma romântica, assegurou que esses homens

não tinham bússola, não possuíam relógio, não conheciam as estrelas: e para que? Olhavam o Itambé, que assoberbava sobranceiro no horizonte, com seu pico sempre coroado de vapores, como o cone gigantesco de um vulcão extinto perfurando as nuvens: era o farol granítico dos viajantes, era o centro de um círculo de sessenta léguas de diâmetro, que podiam revolver sem receio de se extraviarem.

Os marcos naturais do terreno eram evidentemente importantes pontos de referência para a interiorização dos sertanistas pelo território. No relato dos irmãos Nunes, por exemplo, comerciantes que rodaram constantemente pelo Caminho da Bahia entre Vila Rica e Salvador, as montanhas eram uma importante referência. (Furtado, 2013b: 224) Esses pontos geográficos - rios, serras, caminhos - eram transpostos para os roteiros produzidos por esses sertanistas que podiam adquirir a forma cartográfica, como é o caso do conjunto de mapas sertanistas ou relatos escritos, verdadeiros mapas mentais, como era a descrição escrita que os irmãos Nunes deixaram sobre o Caminho da Bahia.

Os homens do sertão também poderiam recorrer os saberes indígenas para se orientarem durante as expedições. Adriano Toledo Paiva (2014: 29), afirma que "[as] representações indígenas assumiram significado operacional em um período no qual a escrita era dominada por poucos", percorrendo espaços completamente singulares e desconhecidos, "os índios não foram somente responsáveis por ensinar as condições de sobrevivência nos sertões e importante força de trabalho nos domicílios, mas também orientaram todas as concepções espaciais da conquista dos sertões" (Paiva, 2014: 30). Os índios tinham um senso de orientação muito bem desenvolvido, pois essa era uma atividade vital, uma questão de sobrevivência na natureza, consequentemente, tinham "uma aguda consciência do espaço geográfico e a capacidade para o representar" (Cortesão, 1965: 26).

No entanto, também podemos supor que os sertanistas se valiam tanto de instrumentos científicos como de conhecimentos práticos como, por exemplo, a observação do sol e das estrelas, importantes instrumentos de referência, mas não é de todo descabido que fizessem uso do astrolábio para tomada das latitudes, facilmente observadas com esse instrumento a partir da declinação do sol, método já conhecido desde a Antiguidade. Ainda que o médico português José Rodrigues Abreu, que fez várias viagens por Minas Gerais, no primeiro decênio do século XVIII, acompanhando o governador Antônio de Albuquerque, não desse muito valor as observações geográficas dos paulistas, a que chamava de práticos, uma vez na capitania, viu "pilotos" tomando as latitudes com instrumentos matemáticos (Furtado, 2003: 174). Outro método comum utilizado pelos paulistas era a transformação de medidas de tempo em distância percorrida, por esta razão a marcha à paulista dividia "o trajeto em jornadas médias de cerca de 37 léguas, 
distância que podia ser transporta em um dia de viagem de caminhada" (Furtado, 2013b: 225).

17 Nos mapas de sertanistas podemos identificar dois traços distintivos sobre os seus usos. De um lado, uma característica evidente desses roteiros era sua utilidade prática, pois serviam diretamente para a orientação das caminhadas, já que neles estavam registrados os caminhos percorridos, os principais marcos naturais do terreno (rios, serras, etc.), como também, quando existentes, os artificiais (picadas, roças, núcleos urbanos, pontes) além dos descobrimentos minerais realizados. Por outro lado, esses documentos podiam ser poderosos instrumentos políticos quando utilizados durante os processos de solicitação de mercês, servindo de prova documental do serviço régio realizado em prol do achamento de riquezas minerais. Como mostrou Francisco Andrade (2008:240) registrar os roteiros pelas minas era de interesse dos próprios sertanistas, pois "eram estes que poderiam fornecer informações fidedignas sobre qualquer pleito de descobrimento", já que a relação de confiança entre os colonos dava credibilidade aos relatos. Além disso, "o conhecimento do itinerário não era um assunto particular, ou de uns poucos membros de uma família", mas sim passava de geração em geração, sendo redesenhado e reinterpretado, constituindo a cartografia sertanistas como um processo coletivo.

Os mapas eram frutos de saberes compartilhados que nasciam e eram modificados a partir das experiências vividas nos sertões. A esse predomínio da experiência vivida no desbravamento do território que se reflete diretamente na produção cartográfica, Adriano Toledo Paiva (2014: 33-34) acrescenta que o repertório movimentado pelos sertanistas na construção dos roteiros e mapas ia além dessas, pois também incorporava a tradição presente em registros escritos, em outros mapas e na própria oralidade. Para a realização completa desses dois usos os mapas deveriam conter elementos carregados de sentido para aqueles que os utilizavam, ou seja, havia um compartilhamento de signos comuns tanto aos cartógrafos como os seus receptores, somente nessa direção que os mapas de sertanistas poderiam completar sua função como instrumentos de comunicação que espacializam as relações sociais (Oliveira, 2012: 82). Ao que tudo indica, os signos desse mundo compartilhado estavam mais próximos da tradição europeia do que da tradição indígena.

\section{Um Roteiro de viagem}

O Mapa de parte de Minas Gerais é um manuscrito, feito à tinta e nanquim, que mede $43 \mathrm{x}$ $60,5 \mathrm{~cm}$, constituindo-se, aparentemente, num típico roteiro de viagem (FBN, 17--a; Costa, 2005: 60). Orientado na direção norte-sul, o mapa compreende a região central e nordeste de Minas Gerais, identificando os limites ao norte, com a Capitania de Pernambuco, e a nordeste, com a da Bahia. 
Figura 1 - Mapa de parte de Minas Gerais

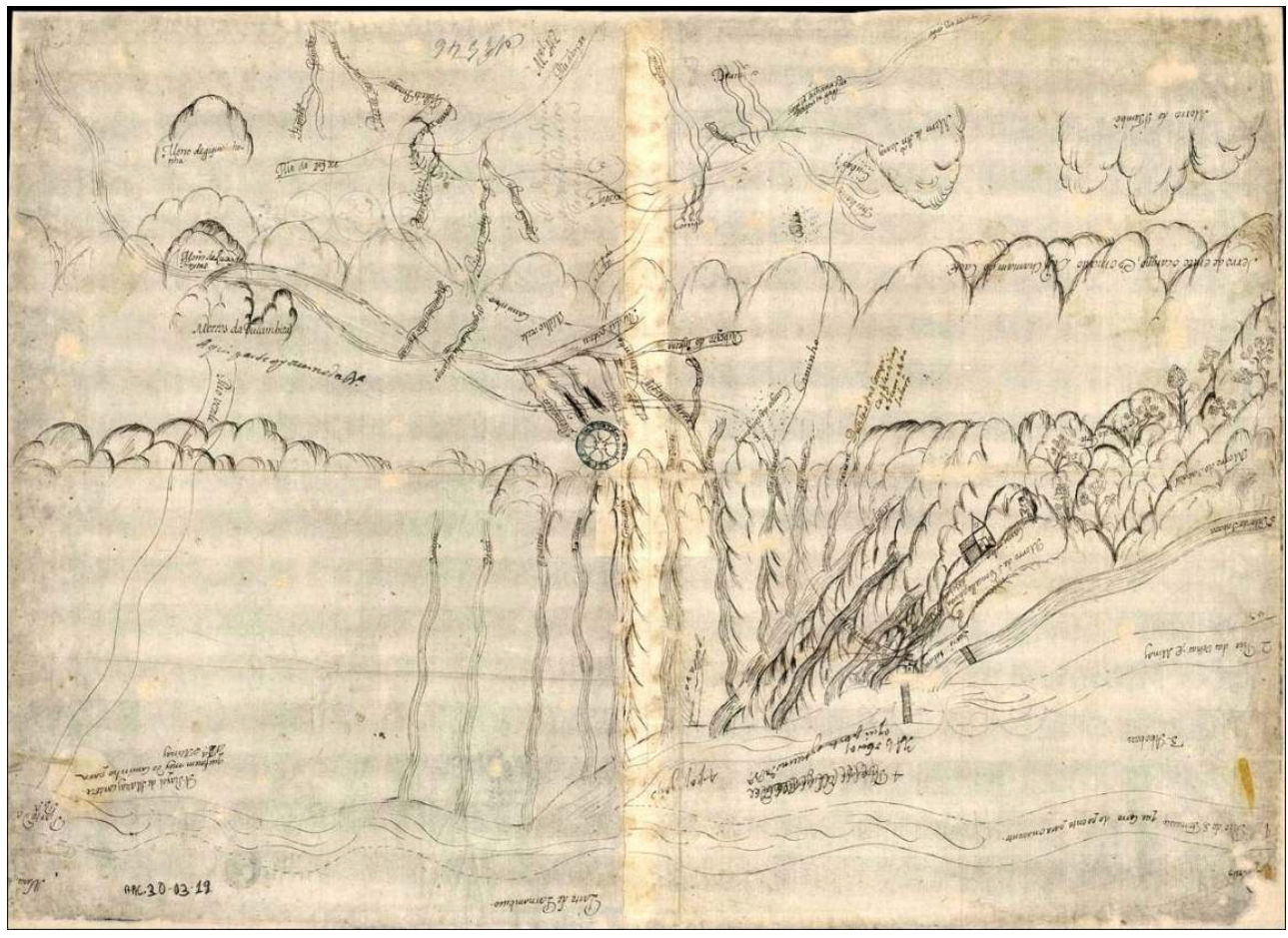

FONTE: FBN - ARC.030,03,019

O Rio São Francisco situado na parte superior da carta estabelece esses limites correndo do sudoeste para o nordeste, ou "do poente para o nascente", nas palavras do autor. A partir da barra do rio das Velhas, a margem esquerda do rio São Francisco aparece apenas tracejada e, na barra do rio Verde há uma indicação de que ali se situa o "arraial de Matias Cardoso, que fazem [sic] meio do caminho para a Bahia e Minas", mas esse caminho não está representado. No que se refere ao Serro do Frio, a carta representa os sertões dessa Comarca e os caminhos que ligam essa região à de Sabará, assim como os principais rios e córregos que cortam a área.

Um caminho principal, com suas ramificações, está desenhado no mapa, sendo seu ponto de partida/ou chegada a barra do Rio Sabará, junto ao Rio das Velhas. Duas pontes distintas cortam, cada uma, o leito desses dois rios nas proximidades da barra do Sabará, onde também está representado o Morro de São Gonçalo, onde a seus pés foi desenhada uma Igreja, que provavelmente indica a existência de um núcleo de povoamento - Sabará -, por sinal o único signo urbano do mapa. Partindo dessa área, o caminho toma a direção sul, quando então corta um grande maciço - o Espinhaço -, de onde vertem inúmeros rios. Logo depois de ultrapassar esses morros, chega-se a uma área plana, o Campo das Congonhas. Nesse ponto, uma trilha secundária, intitulada apenas como "caminho", parte para o sul, até o Morro de Antônio Soares. O ramo principal inflexiona-se, então, para leste, cortando sete ribeirões, entre eles o da Areia e o dos Remédios, sendo que dois deles tiveram seus topônimos rasurados. $\mathrm{O}$ caminho continua para sudeste cortando os rios Jequitinhonha do Campo e Jequitinhonha do Mato, indo em direção ao Morro de Lucas de Freitas, até chegar ao Morro da Tucambira (Itacambira).

Além do Rio São Francisco, dois grandes rios percorrem o mapa: o Rio das Velhas, que recebe como tributário o rio do Sabará, e o rio Verde, que corre no sentido sul-norte até 
verter suas águas do São Francisco, onde se situa o arraial de Matias Cardoso. 0 maciço do Espinhaço, a principal cadeia de montanhas do mapa, é nomeado num trecho como Morro do Sabará, e noutro recebe a denominação de Serro do Frio.

O mapa possui várias observações, descrições e rasuras, que aparentemente foram acrescidas posteriormente, pois foram feitas em caligrafia e tintas diferentes da que prevalece na carta. Dois caminhos, que partem da estrada principal já descrita, representados por traços contínuos, foram incluídos no mapa, um deles, já referido, em sentido sul, começa perto do Campo das Congonhas, passa por Cubas e termina no Morro de Antônio Soares. O outro começa no ribeiro da Areia, em sentido sudeste, passa por Milho Verde até chegar à Vila do Príncipe; de lá, tomando um sentido oeste, continua até atingir também o Morro de Antônio Soares. A inclusão de novas rotas de caminhos terrestre pode ser uma evidência da abertura constante de picadas e estradas que os sertanistas faziam durante suas incursões no sertão.

24 A carta localiza os limites que as Minas Gerais faziam, ao norte, com as Capitanias de Pernambuco e da Bahia, mas a identificação das divisões internas, ou seja, dos limites entre as comarcas dentro da Capitania das Minas, não foi uma preocupação do cartógrafo. Apenas uma pequena descrição que foi, posteriormente, incluída no mapa, marca a área de divisão das comarcas do Sabará e do Serro do Frio, mesmo assim, de forma muito imprecisa. Percebe-se que a identificação de pontos naturais ou de fazendas, arraiais e pousos que existiam pelo Serro do Frio e parte de Sabará eram marcos geográficos de grande importâncias para os sertanistas, pois além de pontos de referência cartográfica eram também importantes postos que serviam para o descanso e o abastecimento dos grupos sertanistas durante as excursões.

Cinco pontos foram numerados no mapa, são eles: "1. Rio de São Francisco que corre do poente para o nascente"; "2. Rio das Velhas, e Minas"; "3. Abóboras"; "4. Papagaio" e "5. Rio do Sabará". Alguns deles sofreram alterações, o que nos fornece indícios sobre os vários usos que o mapa teve ao longo do tempo. O terceiro ponto, Abóboras, por exemplo, foi reposicionado. Inicialmente, estava situado a meio caminho no trecho de terra que separa o rio São Francisco do das Velhas, situado no noroeste da carta. A nova posição, mais a leste, fica junto à ponte que corta o rio das Velhas, na barra do Sabará. Isso pode ter acontecido não devido a um erro do cartógrafo, mas ao reposicionamento do registro das Abóboras, com a construção da ponte. Era nos registros que se cobrava o imposto de passagem. $O$ quarto ponto, Papagaio, também foi rasurado e reposicionado perto do encontro entre os rios São Francisco e das Velhas, o que mais uma vez pode ter sido reflexo da mudança desse posto de registro para um ponto mais estratégico, qual seja o ponto de ligação desses dois grandes rios. De forma geral, a preocupação principal do cartógrafo parece ter sido representar os caminhos dispostos ao longo desse território e, dessa forma, facilitar a orientação do viajante, a partir das referências geográficas naturais - rios, morros, serras. Não é improvável que seu(s) destinatário(s) fosse $(\mathrm{m})$ comerciantes, pois para transportarem suas mercadorias, por exemplo, precisavam saber a localização exata dos registros, que poderiam mudar de posição ao longo do tempo.

A anotação sobre o arraial de Matias Cardoso foi um acréscimo ao mapa original, e é uma indicação da importância do arraial para os que passavam por essas terras. 0 arraial de Matias Cardoso foi fundado ainda no século XVII, quando Mathias Cardoso de Almeida, que comandou e participou de várias bandeiras de apresamento de índios e de combate a quilombolas, se estabeleceu na área de junção do Rio São Francisco com o Rio 
Verde Grande. Por sua posição no sertão, o arraial se desenvolveu a partir da criação de gado e da agricultura, que, inicialmente, era comercializada na Cidade de Salvador. Esse comércio foi tão próspero e intenso que possibilitou o desenvolvimento do arraial e a construção de um caminho de ligação entre o arraial e a cidade, que fazia parte dos chamados caminhos da Bahia. Com o desenvolvimento da atividade mineradora em Minas Gerais, o arraial de Matias Cardoso transformou-se em um importante posto de comércio e de ligação com a Bahia (Carrara, 2007: 587).

O Mapa de parte de Minas Gerais foi desenhado para guiar aquele que o consultasse. A toponímia contida no mapa não segue uma única orientação, podendo assim ser lida de acordo com a posição do consulente do mapa, à medida que se desloca entre os marcos naturais do terreno. Os morros e serras foram desenhados em alto relevo, de forma artística, acentuando suas dimensões e altura, e destacando-os como pontos geográficos importantes para a localização do viajante. Provavelmente a carta foi feita e modificada entre os anos de 1715 a 1720, pois foi durante essa época que a Vila do Príncipe e a comarca do Serro do Frio foram criadas, sendo que a divisão entre as mesmas não foi representada, ao contrário das entre as capitanias vizinhas. Todavia, como esses mapas eram instrumentos compartilhados de saber, o seu tempo de uso pode ter se prolongado por muito mais. O objetivo do mapa era mostrar o caminho de Sabará até o Serro do Frio, com destaque também para a rede hidrográfica. Todavia, como os caminhos foram se proliferando ao longo do tempo, o mapa foi sofrendo alterações, à medida que era manuseado por seus possuidores.

\section{0 roteiro de Lucas de Freitas de Azevedo}

Considerado pela tradição como um dos primeiros moradores da região do Serro do Frio, Lucas de Freitas de Azevedo foi integrante das expedições de Fernão Dias Paes e com isso acumulou um vasto conhecimento geográfico sobre a região.

Já se encontrava estabelecido nas terras do Serro do Frio, aproximadamente, desde 1710, como consta da carta de sesmaria que solicitou sobre as terras do seu sítio do Pé do Morro (Memoriais Municipais, 1896: 755-756). Suas terras, às vezes divididas em lavras velhas ou lavras novas, eram pontos estratégicos nos caminhos do Serro do Frio e constantemente apareciam não só nos mapas e roteiros sertanistas, mas também na cartografia oficial, muitas vezes próximas à possível localização das esmeraldas. Herdeiro da tradição de sertanistas, as ações de descobridor de Lucas de Freitas foram muito bem recebidas e até mesmo incentivas pela Coroa, como prova a carta patente expedida por dom Braz Baltasar:

Tendo consideração ao grande cuidado e despesa em que Lucas de Freitas de Azevedo se ocupa nos descobrimento das esmeraldas e mais pedras preciosas em cuja diligência tem aproveitado de que poderão seguir grandes utilidades à Sua Majestade, que Deus Guarde, e para que o dito Lucas de Freitas se não desanime nesta expedição antes mande com autoridade e respeito as pessoas que nela servirem e com o confiar dele que obrará com o mesmo zelo no dito descobrimento, hei por bem de o nomear e prover no posto de Mestre de Campo do descobrimento das esmeraldas e mais pedras preciosas. (Memoriais Municipais, 1896: 758-759)

Pouco tempo depois, em 1723, Dom Lourenço de Almeida reafirmou a posição de Lucas de Freitas ao incumbi-lo de continuar com os descobrimentos no lugar de Garcia Rodrigues Pais (AHU, Carta de 20 de setembro de 1723). Segundo Sérgio Buarque de Holanda, o fascínio tanto dos sertanistas como dos reinóis pelas esmeraldas foi 
alimentado pelo descobrimento de algumas jazidas ocorrido nas terras americanas de Castela. Buscando nas informações dos índios fatos que comprovassem a proximidade entre os sertões brasileiros e o serro de Potosí, muitos paulistas partiram para os sertões do rio Doce na crença de encontrar um novo Potosí (Holanda, 1959: 158). Segundo Júnia Ferreira Furtado (2012: 433-34), em estudo recente, os roteiros dos sertanistas foram fundamentais para a perpetuação da representação do mito das esmeraldas na cartografia de viés iluminista ao longo do século XVIII. Baseando-se no roteiro dos irmãos Nunes, disponibilizado pelo embaixador português, dom Luís da Cunha, o geógrafo francês Jean Baptiste Bourguignon D'Anville representou com detalhes a região do rio Doce, localizando o serro das Esmeraldas, na sua Carte de l'Amérique méridionale, de 1748. 0 roteiro descrevia que

se estando nas Minas, da conquista de Antônio Dias, o viajante deveria passar ao Rio Doce, subindo esse rio, para o norte, [ali] encontraria o Assui, e, em sua montante, na sua margem norte, encontraria o Rio das Esmeraldas, reconhecido por ter em sua barra uma cachoeira e uma corredeira. Subindo o Assui, em sua nascente, está a lagoa, junto do Serro das esmeraldas, donde já foi povoação e arraial do descobridor delas, Marcos de Azeredo, e na mesma paragem as achou Fernão Dias Paes. (Furtado, 2012, 446)

Segundo os irmãos Nunes, essas informações lhes foram repassadas "por um paulista seu amigo a seguir-lhe nesse empreendimento" (Furtado, 2012: 446). Adriano Toledo Paiva (2013: 46), em tese recente, defende que "o roteiro dos irmãos Nunes foi embasado nos conhecimentos do paulista Lucas de Freitas" que, por ser "considerado descobridor das esmeraldas do Serro do Frio, e integrante das diligências da comitiva de Fernando Dias Paes, foi [ou deve ter sido] o guia mencionado pelos irmãos Nunes". 0 trajeto sugerido por Lucas de Freitas para a serra das Esmeraldas foi, mais tarde, seguido por vários sertanistas que ainda alimentavam as esperanças de encontrá-la. 
Figura 2 - Carta topográfica da vila do Príncipe no Serro Frio e do seu distrito

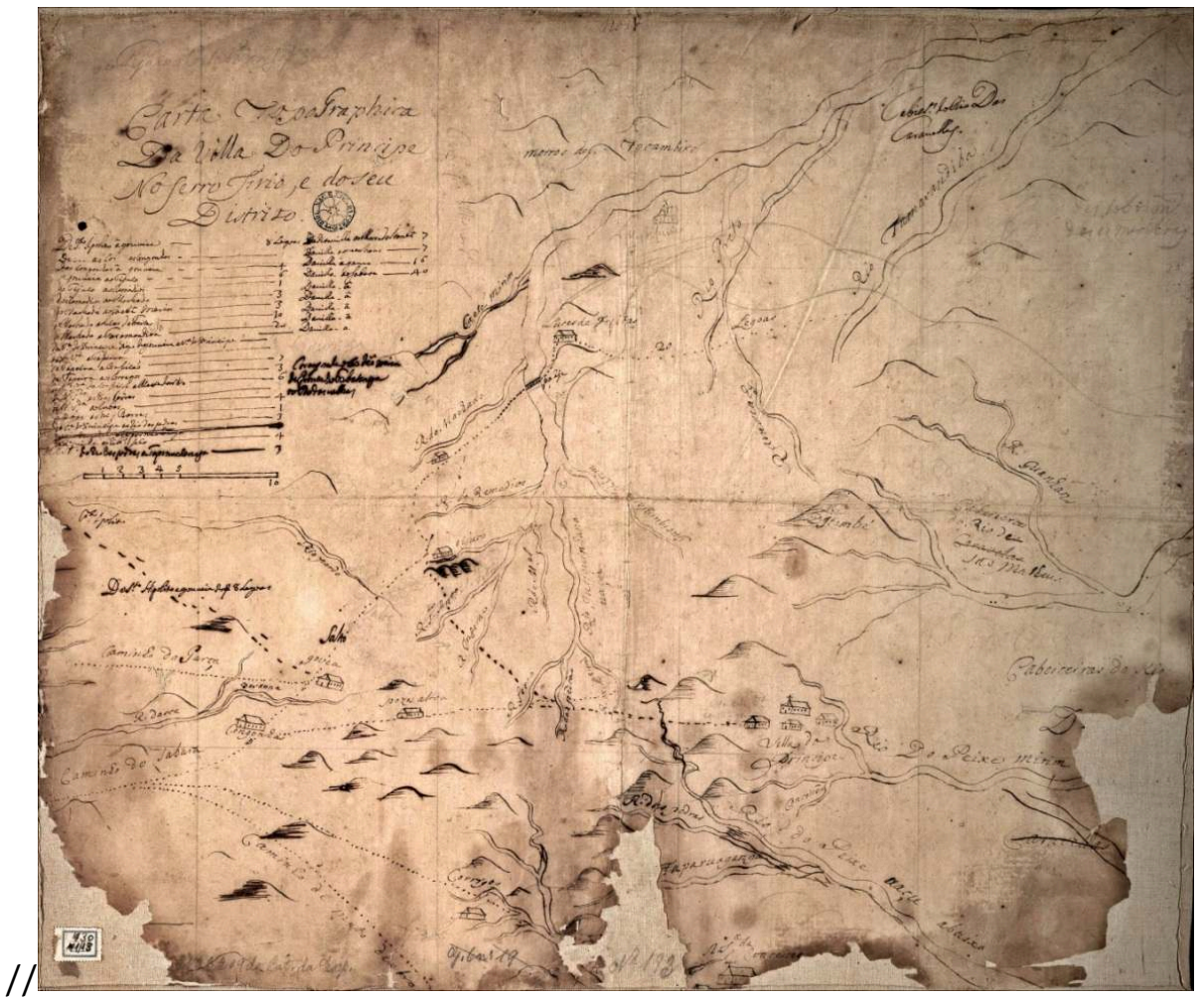

FONTE: FBN - ARC.030,01,013

33 A Carta topográfica da vila do Príncipe no Serro Frio e do seu distrito (FBN, 17--b; Costa, 2005: 61), orientada na direção norte-sul, apresenta claramente o sítio de Lucas de Freitas e o caminho que dali segue para o leste até o rio Itamarandiba, de onde se atingia os "descobrimentos das esmeraldas". O mapa apresenta os caminhos para a Vila do Príncipe e, na sua cartela, estão registradas as distâncias entre as principais localidades representadas. Rios e córregos da região também recebem destaque. O principal é o Jequitinhonha, que corre do centro para o nordeste do mapa, no qual foram identificados os seus principais afluentes, quase todos diamantíferos. Nos sertões do leste, os rios principais são o São Mateus, Guanhães e os dois rios do Peixe.

Desenhado à tinta ferrogálica em papel rústico, com as dimensões 56 x $65,5 \mathrm{~cm}$, o mapa possui diversas observações e descrições à lápis, além de rasuras e acréscimos em outra tinta, que podem ser percebidas pela oxidação do papel e da tinta, que são diferentes das usadas originalmente. Além disso, as bordas principalmente as inferiores, estão bastante desgastadas, inclusive alguns pedaços se perderam, talvez devido ao constante uso que pode ter sido feito desse roteiro.

Os núcleos urbanos, como era habitual na cartografia europeia, foram representados pelo desenho de uma ou mais edificações urbanas. A Vila do Príncipe, próxima ao Rio do Peixe mirim, a sudeste do mapa, se destaca das demais porque o cartógrafo desenhou um ajuntamento de casas em torno de uma igreja, como forma de distinguir seu status de vila em relação aos arraiais, representados por uma única edificação.

No extremo sudeste da carta, corre o Rio do Peixe uaçu a baixo, que está próximo a Tapanhuacanga. Da Vila do Príncipe, a oeste, parte uma linha tracejada que, ao inflexionar-se no sentido norte, passa pelos principais rios diamantíferos, tributários 
do Rio Jequitinhonha Uaçu, são eles: ribeirão do Milho Verde, das Pedras, do Inferno, de Santa Antônio e dos Remédios. Este caminho atinge o arraial do Tejuco, depois segue a nordeste, paralelo ao rio do Machado, atravessa uma ponte até o sítio de Lucas de Freitas, passando a leste pelo Rio Preto, de onde segue até o Rio Itamarandiba.

Da região aurífera, situada a sudoeste, vertem vários caminhos, como o do Mato Dentro que se junta ao caminho do Sabará. Após passar por Congonhas, essa rota se bifurca, uma em direção a Pousos Altos e a Vila do Príncipe, a leste, e outra segue para Gouveia e o arraial do Tejuco, rumo ao nordeste. Mais para o oeste segue o caminho da Garça, a partir do arraial de Gouveia.

Nota-se que o mapa sofreu várias alterações e inclusões posteriores. O sítio de Lucas de Freitas, por exemplo, primitivamente foi representado a tinta por uma casa, depois, foi esboçado a lápis, situado mais ao nordeste da primeira representação, o que evidencia a utilização do mapa como um roteiro ou esboço cartográfico que foi sendo corrigido. Uma nova posição para esse sítio pode ter sido atribuída por outro cartógrafo, que pode ter realizado novas medições ou coletado outras informações sobre esse ponto. Entre os rios Guanhães e Itamarandiba, no nordeste do mapa, foi acrescido à lápis a inscrição: "descobrimento das esmeraldas", outra mostra de que o roteiro foi utilizado durante as excursões dos sertanistas para a busca de riquezas minerais. Outro acréscimo a lápis está na ligação entre o Rio Jequitinhonha Uaçu e o Jequitinhonha Mirim, um círculo com um $\mathrm{x}$ aparece no encontro dos rios, como uma marcação de um tesouro. Infelizmente não conseguimos obter mais informações sobre esse ponto, mas seu desenho não deixa dúvidas de que ali se escondia alguma riqueza. À tinta também foi acrescido ao mapa o caminho de Santo Hipólito até Gouveia, onde está a inscrição: "De Santo Hipólito a Gouveia são 8 léguas", uma mostra de que alguém utilizou o mapa e percorreu esse caminho, e para auxiliar no uso prático do mapa, decidiu escrever ali a distância entre os dois pontos. Outra marcação relacionada com os percursos no sertão foi a inclusão de um Salto no caminho entre Gouveia e o Tejuco.

Abaixo do título do mapa, há uma extensa legenda que representa as distâncias em léguas entre a Vila do Príncipe, os arraiais, os lugarejos e os rios e córregos da região. Este roteiro tinha como objetivo representar os principais percursos do Serro do Frio que passavam pelas ricas minas de ouro, diamantes e até esmeraldas. $O$ conhecimento sobre as distância se mostra o objetivo principal, não só por causa da extensa legenda, mas também por causa da escala, que está logo abaixo. A utilização desse recurso é uma evidência de que as distâncias do mapa foram pensadas em proporções, para que pudessem ser medidas a partir do próprio mapa e assim auxiliar os viajantes em seus percursos. Identifica-se, portanto, o uso de códigos cartográficos europeus nesse mapa de sertanista, o que mostra que não só o cartógrafo conhecia as convenções e recursos cartográficos comuns na Europa, mas também os consumidores do mapa compartilhavam desse conhecimento, pois, se não o tivessem, não saberia como interpretar o mapa.

De acordo com Júnia Ferreira Furtado (2013b: 178), os irmãos Nunes se estabeleceram em Minas Gerais entre os anos 1709 a 1724. Percorreram, principalmente, a rota comercial entre a Capitania e Salvador, mas também conheceram outras rotas comerciais, como a do Rio de Janeiro. Em Minas, mantiveram ligações com os cristãosnovos da região de Pitangui e também conheceram o Serro do Frio, onde as notícias sobre as esmeraldas eram abundantes. $O$ período de permanência dos irmãos nas Minas coincide com o momento de ascensão de Lucas de Freitas, e tudo leva a crer que o 
conheceram quando este já era "Mestre de Campo do Descobrimento das Esmeraldas", portanto, esse mapa poder ter sido elaborado próximo a década de 1720 .

Não se pode afirmar, com certeza, que além do ouro, estes mapas representavam os descobertos de diamantes, mas pela história da mineração das pedras, em que os descaminhos, extravios, garimpos e contrabandos estavam presentes desde o início, é bem provável que poderiam ser exemplares do caminho para essas novas descobertas. Como afirmou dom Lourenço de Almeida em carta para dom João V:

Pela Bahia e Pernambuco ainda é maior a quantidade de ouro, que se tira destas Minas sem se pegar os quintos, porque são mais dilatados estes sertões, e muito mais fáceis de vadiar por qualquer parte, sem que seja pelas estradas gerais e além destas se não tem a comodidade de o levarem pelas Minas Novas do Serro Frio, que estão unidas com estas, e somente quadro dias de jornada da Vila do Príncipe, e dizendo que é ouro tirado nestas e chamadas minas o levam para a Bahia com uma carta de guia. (AHU, Carta de 17 de janeiro de 1730)

\section{Conclusão}

Voltando às perguntas que fizemos no início podemos perceber depois desse percurso que a participação do conhecimento indígena nativo na produção desses mapas não se mostra de forma clara, por outro lado o uso das tradições cartográficas europeias se faz presente quando vemos a utilização de signos convencionados tanto na representação dos elementos naturais (como serras, rios e montes) como nos elementos artificiais (arraiais, vilas, pontes, estradas). Porém, a utilização desses signos está intimamente ligada com a relação prática que eles mantinham com o território, afinal, o que interessava não era o rigor científico, mas sim a utilidade prática. Nesse sentido, esses mapas são representantes de uma cartografia sábia, porque representam um acúmulo de conhecimentos que mescla elementos de uma tradição cartográfica mais profissional com o conhecimento da sabedoria do território.

o que percebemos é que a cartografia dos mapas de sertanistas mantinha uma relação política e social com os territórios representados por meio de suas rústicas técnicas. Esses mapas definitivamente não tinha uma pretensão de serem espelhos da realidade, mas tinham como objetivo mobilizar um conhecimento prático, útil e significativo para proporcionar a exploração econômica dos sertões do Serro do Frio. Essa caraterística fez com que os mapas de sertanistas circulassem no mundo colonial, ainda, claro, que de modo restrito.

Foi com o recurso da perspectiva da Nova História da Cartografia que procuramos desvendar os contextos desses mapas, indo muito além da análise objetiva da geografia que representam para tentar compreender o universo cultural em que estavam imersos e com o qual dialogavam. 


\section{BIBLIOGRAFIA}

\section{Arquivos}

BNB - Fundação Biblioteca do Brasil, Rio e Janeiro.

AHU - Arquivo Histórico Ultramarino, Lisboa.

Arquivo da Câmara Municipal da Cidade do Serro (Minas Gerais, Brasil).

Fontes

\section{1 - Documentos}

AHU. Conselho Ultramarino. Brasil/Minas Gerais. Cx.4, Doc. 67. 20/09/1723. Carta de D. Loureço de Almeida, governador das Minas Gerais, dando conta da diligência que entregou aos paulistas Lucas de Freitas, capitão Alberto Dias e Domingos Dias Ribeiro, para o descobrimento das esmeraldas.

AHU. Conselho Ultramarino - 011. Cx.16, D.1252. Carta de D. Lourenço de Almeida, governador de Minas, para D. João V, dando uma informação detalhada sobre o estado da Capitania, com especial realce para a mineração do ouro e a descoberta de diamantes. 1730, Janeiro 17, Vila Rica. AHU on-line. Documentação Manuscrita. Disponível em: <http://siarq.iict.pt/_ Acesso em 22 mar. 12. AHU. Carta de 4 da julho de 1730. Documentos Avulsos, Rio de Janeiro, 1730.

Memoriais Municipais. Arquivo da câmara municipal da Villa do Príncipe hoje cidade do Serro. Revista do Arquivo Público Mineiro. Ouro Preto: Arquivo Público Mineiro, v.01, fasc.04, out/dez 1896.

\section{2 - Mapas}

BNB(a). Mapa de parte de Minas Gerais. [17--]. Desenho a tinta e nanquim, 43 x 60,5 cm. ARC. 030,03,019. BNDigital. Disponível em <http://objdigital.bn.br/acervo_digital/div_cartografia/ cart514099.jpg> Acesso em 10 mar. 12.

BNB(b). Carta topográfica da Vila do príncipe no Serro Frio e do seu distrito. [17--]. Desenho a tinta ferrogálica, 56 x 65,5 cm. ARC.030,01,013. BNDigital. Disponível em <http://objdigital.bn.br/ acervo_digital/div_cartografia/cart525842.jpg> Acesso em 10 mar.12.

\section{Bibliografia}

Andrade, Francisco Eduardo de (2008). A invenção das Minas Gerais: empresa, descobrimentos e entradas nos sertões do ouro da América portuguesa. Belo Horizonte: Autêntica e PUC Minas.

Carrara, Ângelo Alves (2007). Antes das Minas Gerais: conquista e ocupação dos sertões mineiros. Varia História, Belo Horizonte, vol.23, n³8, Jul/Dez, pp. 574-596.

Cortesão, Jaime (1965). História do Brasil nos velhos mapas, v. 1. Rio de Janeiro: Ministério das Relações Exteriores, Instituto Rio Branco.

(1971). História do Brasil nos velhos mapas, v. 2. Rio de Janeiro: Ministério das Relações Exteriores, Instituto Rio Branco. 1965-1971.

(2009). História do Brasil nos velhos mapas. Tomo II. Lisboa: Imprensa Nacional, Casa da Moeda. Costa, Antônio Gilberto, org. (2005). Os caminhos do Ouro e a Estrada Real. Belo Horizonte: UFMG; Lisboa: Kapa. 
Edney, Mattew (2007). A história da publicação do Mapa da América do Norte de John Mitchell de 1755. Varia Historia, Belo Horizonte, v.23, n.37, jan/jun, pp.30-50,.

Furtado, Júnia F (2003). As índias do conhecimento ou a geografia imaginária da conquista do ouro. Anais de História de Além-mar, Lisboa, v.4, pp.155-212.

(2012). Oráculos da geografia iluminista. Dom Luís da Cunha e Jean-Baptiste Bourguignon D’Anville na construção da cartografia do Brasil. Belo Horizonte: Ed. UFMG.

(2013a). O mapa que inventou o Brasil. São Paulo: Versal Editores.

(2013b). Trajetórias carto-geográficas de uma família de cristãos-novos dos sertões das Gerais aos cárceres da Inquisição: o caso dos irmãos Nunes. In: Furtado, Júnia F. e Resende, Maria Leônia Chaves de. (orgs.) Travessias inquisitoriais das Minas Gerais aos cárceres do Santo Ofício: diálogos e trânsitos religiosos no império luso-brasileiro (sécs. XVI - XVIII). Belo Horizonte: Fino Traço.

Harley, John Brian (2005). Textos y contextos en la interpretación de los primeros mapas. In: La nueva naturaleza de los mapas: ensayos sobre la historia de la cartografía. México: Fonde de Cultura Económica.

Holanda, Sérgio Buarque de (1959). Visão do paraíso: os motivos edênicos no descobrimento e colonização do Brasil. Rio de Janeiro: José Olympio Ed.

Lima Jr, Augusto de (1945).. História dos diamantes nas Minas Gerais. Rio de Janeiro, Livros de Portugal.

Oliveira, Tiago Kramer (2012). Desconstruindo velhos mapas, revelando espacializações: a economia colonial no centro da América do Sul (primeira metade do século XVIII). Tese, Doutorado em História. São Paulo: USP.

Paiva, Adriano Toledo (2013). “Aranzéis da tradição”: conquistadores nos sertões do ouro (1760-1800). Tese, Doutorado em História. Belo Horizonte: UFMG.

Rodrigues, Carmem Marques (2014). Os mapas das pedras brilhantes: a cartografia dos sertanistas, dos engenheiros militares e dos padres matemáticos sobre o Distrito Diamantino do Serro do Frio (1714-1771). Dissertação, Mestrado em História. Belo Horizonte: UFMG.

Santos, Joaquim Felício dos (1976). Memórias do distrito diamantino da Comarca do Serro do Frio. 4eed. Belo Horizonte: Itatiaia. São Paulo: USP.

\section{RESUMOS}

A partir da metodologia da Nova História da Cartografia analisamos dois mapas sertanistas do Serro do Frio, buscando desvelar seus contextos e dialogar com a visão clássica formulada por Jaime Cortesão sobre os mapas sertanistas, propondo a utilização dos mapas como fontes históricas complexas que nos apresentam muito mais informações do que aquelas relacionadas a representação do território.

A partir de la nueva historia de la metodología Cartografía analizó algunos mapas sertanistas del Serro Frío, tratando de descubrir su contexto y el diálogo con la visión clásica formulada por Jaime Cortesão, proponiendo el uso de mapas como fuentes históricas complejas que comprenden mucho más información que los estrictamente relacionados con la representación del territorio.

From the methodology of the New History of Cartography, we analyze two sertanistas maps, seeking to reveal their contexts and to dialogue with the classic vision formulated by Jaime 
Cortesão, proposing the use of maps as complex historical sources that present us with much more information than those related to the representation of the territory.

De la Nouvelle Histoire de la Cartographie analysé deux cartes sertanistas du Serro Frio, en cherchant à découvrir leur contexte et le dialogue avec la vision classique formulée par Jaime Cortesão, proposant l'utilisation des cartes comme sources historiques complexes avec le très plus d'informations que celles qui sont liées à la représentation du territoire.

\section{ÍNDICE}

Índice geográfico: Brasil, Minas Gerais, Serro do Frio

Palavras-chave: Nova história da cartografia, mapas sertanistas, Serro do Frio

Palabras claves: Nueva historia de la cartografia, mapas sertanistas, Serro do Frio

Índice cronológico: $1700-1750$

Keywords: New history of cartography, sertanistas maps, Serro do Frio

Mots-clés: Nouvelle histoire de la cartographie, cartes sertanistas, Serro do Frio

\section{AUTOR}

\section{CARMEM MARQUES RODRIGUES}

Doutoranda em História da Ciência pela Universidade Federal de Minas Gerais / CAPES 